\title{
IMPACT OF OVERWEIGHT AND \\ OBESITY ON CARDIAC DIASTOLIC
}

\section{FUNCTION}

Neslihan Soysal Atile ${ }^{1}$, Derya Baykız², Betül Ekiz Bilir , Bülent Bilir ${ }^{3}$

${ }^{1}$ Tekirdağ State Hospital, Endocrinology and Metabolism Department, Tekirdağ, Turkey

${ }^{2}$ Tekirdağ State Hospital, Cardiology Department, Tekirdağ, Turkey

${ }^{3}$ Namık Kemal University Faculty of Medicine, Internal Medicine Department, Tekirdağ, Turkey

- Introduction: Left ventricular diastolic dysfunction (LVDD) is a common cause of heart failure in obese patients. The aim of this study is to evaluate diastolic function and its relation to body mass index (BMI) in overweight and obese patients by using transthoracic echocardiography.

- Material-Method: A total of 133 cases were enrolled in the study. All anthropometric and laboratory measures were recorded. After measuring two-dimensional and M-mode echocardiographic variables, left and right ventricle diastolic functions were evaluated by conventional and tissue Doppler imaging. The patients with diabetes mellitus, hypertension and any kind of cardiovascular disease were excluded from the study.

- Results: BMI was positively correlated with systolic and diastolic blood pressures and laboratory measures of HOMA-IR, low density lipoprotein (LDL) and proBNP. BMI was positively correlated with left atrium (LA) and left ventricul (LV) end-diastolic, end-systolic diameters, thickness of the wall of the LV, LA volume indices and LV mass indices ( $p=0,000)$. When tissue Doppler diastolic parameters were evaluated for right and left ventricul; BMI was negatively correlated with mitral septal annulus $E^{\prime}(p=0,022)$, and positively correlated with LV end-diastolic filling index $\mathrm{E} / \mathrm{e}^{\prime}(\mathrm{p}=0,005)$, tricuspid annulus $\mathrm{E}^{\prime}(\mathrm{p}=\mathrm{o}, \mathrm{0} 49)$, tricuspid annulus $\mathrm{A}^{\prime}$ $(\mathrm{P}=0,006)$, tricuspid annulus peak myocardial systolic velocity $(\mathrm{Sa})$ $(\mathrm{p}=\mathrm{o}, \mathrm{o04})$. Pro-BNP was negatively correlated with mitral annulus E' $(\mathrm{p}=0,007)$ and positively correlated with left atrium and ventricular diameters ( $\mathrm{p}=\mathrm{o}, \mathrm{0} 27$ and $\mathrm{o}, 008$ respectively), left atrium volume index $(\mathrm{p}=0,000)$ and $\mathrm{E} / \mathrm{e}^{\mathrm{j}}(\mathrm{p}=\mathrm{o}, 029)$.

- Conclusion: Overweight and obesity have a negative impact on diastolic function as assessed by tissue Doppler imaging. Positive correlation between BMI and pro-BNP levels may call attention to potential value of pro-BNP as a marker of diastolic dysfunction. 